\title{
Residue, Dissipation Pattern, and Dietary Risk Assessment of Imidacloprid in Chinese Chives
}

\author{
Rongqi Zhai ${ }^{1}$, Kaige Zhang ${ }^{1}$, Ge Chen ${ }^{1 *}$, Guangyang Liu ${ }^{1}$, Xiaodong Huang ${ }^{1}$, \\ Mingkun Gao ${ }^{1}$, Jie Zhou ${ }^{1}$, Xiaomin Xu ${ }^{1}$, Lingyun $\mathrm{Li}^{1}$, Yanguo Zhang ${ }^{1}$, Jing Wang ${ }^{2}$, \\ Maojun $\mathrm{Jin}^{2}$, Donghui Xu ${ }^{1 *}$ and A. M. Abd El-Aty ${ }^{3,4}$
}

'Key Laboratory of Vegetables Quality and Safety Control, Laboratory of Quality \& Safety Risk Assessment for Vegetable Products, Institute of Vegetables and Flowers, Ministry of Agriculture and Rural Affairs, Chinese Academy of Agricultural Sciences, Beijing, China, ${ }^{2}$ Key Laboratory of Agro-Product Quality and Safety, Institute of Quality Standard and Testing Technology for Agro-Products, Ministry of Agriculture and Rural Affairs, Chinese Academy of Agricultural Sciences, Beijing, China, ${ }^{3}$ Department of Pharmacology, Faculty of Veterinary Medicine, Cairo University, Giza, Egypt, ${ }^{4}$ Department of Medical Pharmacology, Faculty of Medicine, Atatürk University, Erzurum, Turkey

The demand for Chinese chives is growing as they are also rich in vitamins, fiber, and sulfur nutrients. Chinese chives should be sprayed with imidacloprid to control pests and diseases to safeguard their yield and to meet the demands of East Asian consumers for Chinese chives. Overspraying of imidacloprid can lead to residues in Chinese chives, posing a severe risk to human health. To reduce the harmful effects of imidacloprid residues on humans, we investigated the imidacloprid dissipation pattern and the final residue on Chinese chives using the quick, easy, cheap, effective, rugged, and safe (QuEChERS) method combined with liquid chromatography-tandem mass spectrometry (LC-MS/MS). Good linearity $\left(R^{2}=0.9988\right)$, accuracy (expressed as recovery \% of 78.34-91.17\%), precision [expressed as relative SDs (RSDs) of 0.48-6.43\%], and sensitivity [a limit of quantification (LOQ) $\leq 8.07 \times 10^{4} \mathrm{mg} / \mathrm{kg}$ ] were achieved. The dissipation dynamics were consistent with the first-order kinetics, with a half-life of 2.92 days. The final residual levels on Chinese chives were $0.00923-0.166 \mathrm{mg} / \mathrm{kg}$, which is lower than the maximum residue limits (MRLs) of $1 \mathrm{mg} / \mathrm{kg}$ for imidacloprid on Chinese chives. A risk assessment index of $<1$ indicates that Chinese chives are safe for consumption.

Keywords: imidacloprid pesticides, dissipation dynamics, Chinese chives, sample preparation, risk assessment

\section{INTRODUCTION}

Chinese chives (Allium tuberosum) are among the most important vegetables to East Asians (1). It is rich in vitamins, fiber, and sulfur compounds with antiseptic properties $(2,3)$. According to traditional Chinese medicine, it has aphrodisiac, anti-cancer, antioxidant, and other healing properties and treats abdominal pain and asthma (4-6). Modern medicine shows that the dietary fiber in Chinese chives could promote intestinal peristalsis and accelerate the body's metabolism, thereby preventing colorectal cancer. It also decreases cholesterol absorption and prevents atherosclerosis and coronary heart disease $(7,8)$. Therefore, the economic value of chives is increasing, which leads to the expansion of the planting area.

As Chinese chives are planted on a large scale, plant pests and diseases increased accordingly. The Chinese chives maggot (Bradysiaodoriphaga), with a short reproductive cycle, high fertility, 
TABLE 1 | Imidacloprid elution conditions.

\begin{tabular}{cccc}
\hline $\begin{array}{c}\text { Time } \\
(\mathbf{m i n})\end{array}$ & $\begin{array}{c}\text { Flow rate } \\
(\mathbf{m L} / \mathbf{m i n})\end{array}$ & $\begin{array}{c}\text { Methanol } \\
\mathbf{( \% )}\end{array}$ & $\begin{array}{c}\text { Ammonium acetate } \\
\text { solution (1 mmol,\%) }\end{array}$ \\
\hline 0 & 0.3 & 20 & 80 \\
8 & 0.3 & 95 & 5 \\
12 & 0.3 & 95 & 5 \\
12.1 & 0.3 & 20 & 80 \\
\hline
\end{tabular}

and overwintering under protected conditions, becomes an annual pest occurrence (9). The rate of affected plants can reach $20-50 \%$. The damage of Chinese chives maggot is the most severe problem (10). Farmers spray imidacloprid to control pests, which acts as an inhibitor of nicotinic acetylcholine receptors (nAChRs) in the central nervous system of insects, causing disruption of the insect's nervous system and, eventually, leading to death $(11,12)$. It fails to decompose thoroughly, resulting in long residual levels (13) that would result in harmful health effects.

The residue dissipation of imidacloprid has been reported in Chinese chives. However, few studies detected the imidacloprid residues using a liquid chromatography-tandem mass spectrometry (LC-MS/MS), and assessed its dietary risk in Chinese chives $(14,15)$. Studying pesticide residues and dissipation of imidacloprid is vital in Chinese chives because of its high residual pesticide and less-relevant dissipation dynamics (16). This study developed a method to analyze the imidacloprid residues in Chinese chives using QuEChERS combined with LC-MS/MS. Furthermore, we determined the dissipation pattern and the dietary risk assessment to help planters to further master the spraying and the harvesting period of imidacloprid in Chinese chives, thus, reducing the risk to the environment and the human health. Secondly, the study further explored the quick sample preparation of imidacloprid in Chinese chives. Finally, the study compared the recoveries, relative SDs (RSDs) of QuEChERS, and quick extraction to select a more suitable sample preparation for imidacloprid in Chinese chives.

\section{MATERIALS AND METHODS}

\section{Chemicals and Equipment}

Imidacloprid, water-dispersible granules ( $10 \%$ WG), was obtained from Hebei Noda Agrochemical Co., Ltd. Imidacloprid standard (100 mg/kg), was procured from Beijing Manhage Bio-Technology Co. Ltd. Acetonitrile (chromatographic grade), and was purchased from Merck AG, Germany. Anhydrous magnesium sulfate (analytical grade) was secured from Xilong Chemical Co., Ltd. Sodium chloride (analytical grade) and was supplied by Tianjin Huihang Chemical Technology Co., Ltd. Dispersed solid-phase extraction purifier (52-mg PSA; 52-mg C18; 26-mg GCB) was obtained from Shimadzu Corp. (Kyoto, Japan).

\section{Field Experiment and Sampling}

Final residue and dissipation field trials were carried out following the "Guideline for Testing of Pesticide Residues in
Crops" (NY/T 788-2018) (Ministry of Agriculture and Rural Affairs of the People's Republic of China, 2018). The final residual experiments were conducted in May 2020 at Tongzhou Beijing. The experiment set up a protective belt around each $50-\mathrm{m}^{2}$ plot, including a control plot without application of imidacloprid, an experiment plot of imidacloprid dissipation, and an experiment plot of final imidacloprid residue was reserved during the whole growth period.

Imidacloprid, at $10 \% \mathrm{WG}$, was applied at a dosage of 0.429 $\mathrm{g} / \mathrm{L}$ when Chinese chives grew to $10-30 \mathrm{~cm}$ to investigate its dissipation. Fresh samples of at least $2 \mathrm{~kg}$ Chinese chives that have been drugged and are growing normally were randomly collected from 24 points of each plot. The fresh samples were collected and packed into sample containers that were wrapped and labeled after 2 h, 8 days, 18 days, and 25 days following the last application.

Soil and wilted leaves attached to the Chinese chives were removed. The samples were cut and mixed, homogenized with a beater, and packed into sample boxes. The sample boxes were labeled and stored at $-20^{\circ} \mathrm{C}$ in the refrigerator.

\section{Sample Preparation}

As the composition of Chinese chives substrate is more complex than other vegetables, the sample preparation was carried out with two different methods.

Method 1 (QuEChERS): Chinese chives homogenate (10 g) was weighed and placed in a $50-\mathrm{mL}$ centrifuge tube. Then, $10-$ $\mathrm{mL}$ acetonitrile was added to the centrifuge tube and vortexed for $1 \mathrm{~min}$. After that, 4-g anhydrous magnesium sulfate and 1g sodium chloride were added, vortexed again for $1 \mathrm{~min}$, and centrifuged at $6,000 \mathrm{r} / \mathrm{min}$ for $5 \mathrm{~min}$. The supernatant $(9 \mathrm{~mL})$ was transferred to a $50 \mathrm{~mL}$ centrifuge tube containing $90-\mathrm{mg}$ dispersed solid-phase extraction purifier, vortexed for $30 \mathrm{~s}$, and centrifuged at $6,000 \mathrm{r} / \mathrm{min}$ for $2 \mathrm{~min}$. The sample was filtered through a $0.22-\mu \mathrm{m}$ membrane and transferred into a glass vial for LC-MS/MS.

Method 2 (quick extraction): Chinese chives homogenate ( $1 \mathrm{~g}$ ) was weighed and was placed in a $10-\mathrm{mL}$ centrifuge tube. Next, $4 \mathrm{~mL}$ of an aqueous solution of 2, 5, and $10 \%$ of methanol were added respectively to the different centrifuge tubes, shaken manually for $30 \mathrm{~s}$, and left undisturbed for $1 \mathrm{~min}$. The sample was filtered through a $0.22-\mu \mathrm{m}$ membrane and transferred into a glass vial for LC-MS/MS.

\section{Liquid Chromatography-Tandem Mass Spectrometry (LC-MS/MS)}

A Shimadzu LC-30A, MS8050 HPLC-MS/MS (Shimadzu Corp., Kyoto, Japan) instrument, equipped with an electrospray ionization (ESI), was adopted here. A Phenomenex-C18 column $(50 \mathrm{~mm} \times 3 \mathrm{~mm}, 2.6 \mu \mathrm{m})$ with an injection volume of $1 \mu \mathrm{L}$; column temperature of $40^{\circ} \mathrm{C}$; flow rate of $0.3 \mathrm{ml} / \mathrm{min}$; and elution conditions are shown in Table 1. The mass spectrometer was operated with electrospray in the positive ion mode $\left(\mathrm{ESI}^{+}\right)$, and the ions were monitored in the multiple reaction monitoring (MRM) mode. Mass spectrometric conditions: ion source temperature $400^{\circ} \mathrm{C}$; ion pairs and collision energy and other parameters are shown in Table 2. 
TABLE 2 | Characteristic monitoring ion of imidacloprid.

\begin{tabular}{|c|c|c|c|c|c|c|}
\hline Name & Qualitative ion $(\mathrm{m} / \mathrm{z})$ & Quantification ion $(\mathrm{m} / \mathrm{z})$ & Retention time /min & Q1 Pre bias/V & Q3 Pre bias /V & Collision energy /eV \\
\hline Imidacloprid & $256.10 / 175.10$ & $256.10 / 209.10$ & 2.701 & $-27-27$ & $-27-22$ & $-16-14$ \\
\hline
\end{tabular}

\section{Dissipation Kinetics}

The residue levels of imidacloprid on Chinese chives decreased with application time in Chinese chives, expressed by the firstorder kinetic equation:

$$
\begin{gathered}
C_{t}=C_{0} e^{-k t} \\
T_{1 / 2}=\ln 2 / k
\end{gathered}
$$

where $\mathrm{C}_{\mathrm{t}}$ and $\mathrm{C}_{0}$ represent the pesticide residual levels $(\mathrm{mg} / \mathrm{kg})$ at times $t$ and 0 (days), respectively.

\section{Dietary Exposure Assessment}

We assessed the risk of imidacloprid in Chinese chives using a chronic dietary risk quotient (RQc) based on a risk factor approach (17).

$$
\begin{gathered}
R Q c=\frac{N E D I}{A D I} \\
N E D I=\frac{\sum(F i \times S T M R)}{b w}
\end{gathered}
$$

NEDI (mg/kg. bw/day): the national estimated daily intake; Fi (kg/day): the average daily per capita consumption of a particular food in China; STMR ( $\mathrm{mg} / \mathrm{kg})$ : supervised trials median residue; bw: the average body weight of Chinese adults $(63 \mathrm{~kg})$; ADI (mg/kg bw/day): the acceptable daily intake.

$$
\begin{gathered}
R Q a=\frac{N E S T I}{A R f D} \\
N E S T I=\frac{L P \times H R}{b w}
\end{gathered}
$$

NESTI (mg/kg.bw/day): the national estimated short-term intake; LP (kg/day): the large portion of specific food item consumed per day; HR $(\mathrm{mg} / \mathrm{kg})$ : the highest residue; ARfD (mg/kg.bw/day): the acute reference dose. ARfD of imidacloprid was established to be $0.4 \mathrm{mg} / \mathrm{kg} \cdot \mathrm{bw} /$ day.

According to Mao et al. (18), the per capita annual consumption of Chinese chives was $33.40 \mathrm{~kg}$, and the Fi of Chinese chives was $0.0915 \mathrm{~kg} /$ day. As the LP of Chinese chives was not reported, it has to be replaced by dark green vegetables $(\mathrm{LP}=0.5 \mathrm{~kg})(19)$. The RQ $<1$ and RQ $>1$ indicate whether the risk of the evaluated pesticide is acceptable and unacceptable to consumers, respectively.

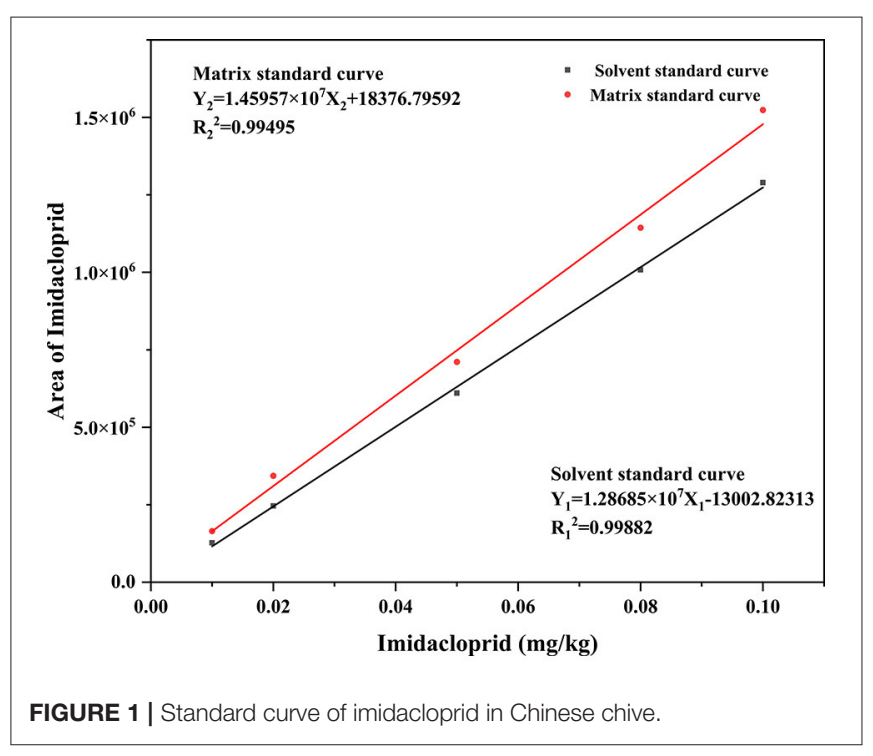

\section{RESULTS AND DISCUSSION}

\section{Method Validation}

According to NY/T 788-2018, the analytical method was validated using accuracy, precision, quantification limit, detection limit, matrix effect (ME), and linearity. The method's linearity was evaluated by plotting matrix-matched calibration curves at five concentrations within $0.01-0.10 \mathrm{mg} / \mathrm{kg}$. The ME represents the ratio of the slope of the matrix matching curve to the slope of the solvent curve. The values $>1$ and $<1$ represent a signal enhancement and suppression effects, respectively (20). The imidacloprid standard was prepared in acetonitrile and blank solution at a concentration rate of $0.01,0.02,0.05,0.08$, and $0.1 \mathrm{mg} / \mathrm{kg}$. The solvent and matrix-matched calibrations for imidacloprid are $\mathrm{Y}_{1}=1.28685 \times 10^{7} \mathrm{X}_{1}-13002.82313, R_{1}^{2}=$ 0.99882 and $\mathrm{Y}_{2}=1.45957 \times 10^{7} \mathrm{X}_{2}+18376.79592, R_{2}^{2}=0.99495$ (Figure 1). The calculated ME was $>1$, denoting that the Chinese chives mechanism has an enhancement effect.

Accuracy and precision are expressed as recovery (recovery of $70-120 \%$ ), and relative standard deviation (RSD $\leq 20 \%$ ) is according to NY/T 788-2018 (21). The average recoveries of imidacloprid were $78.34-91.17 \%$, with RSD between 0.48 and 6.43\% using QuEChERS; the finding that met the NY/T788-2018 requirements. These results showed a satisfactory accuracy and precision of imidacloprid in Chinese chives matrices.

\section{Comparison of QuEChERS and Quick Extraction}

The extraction efficiency (expressed as recovery \pm RSD) of the 2 tested methods was assessed by spiking three different 


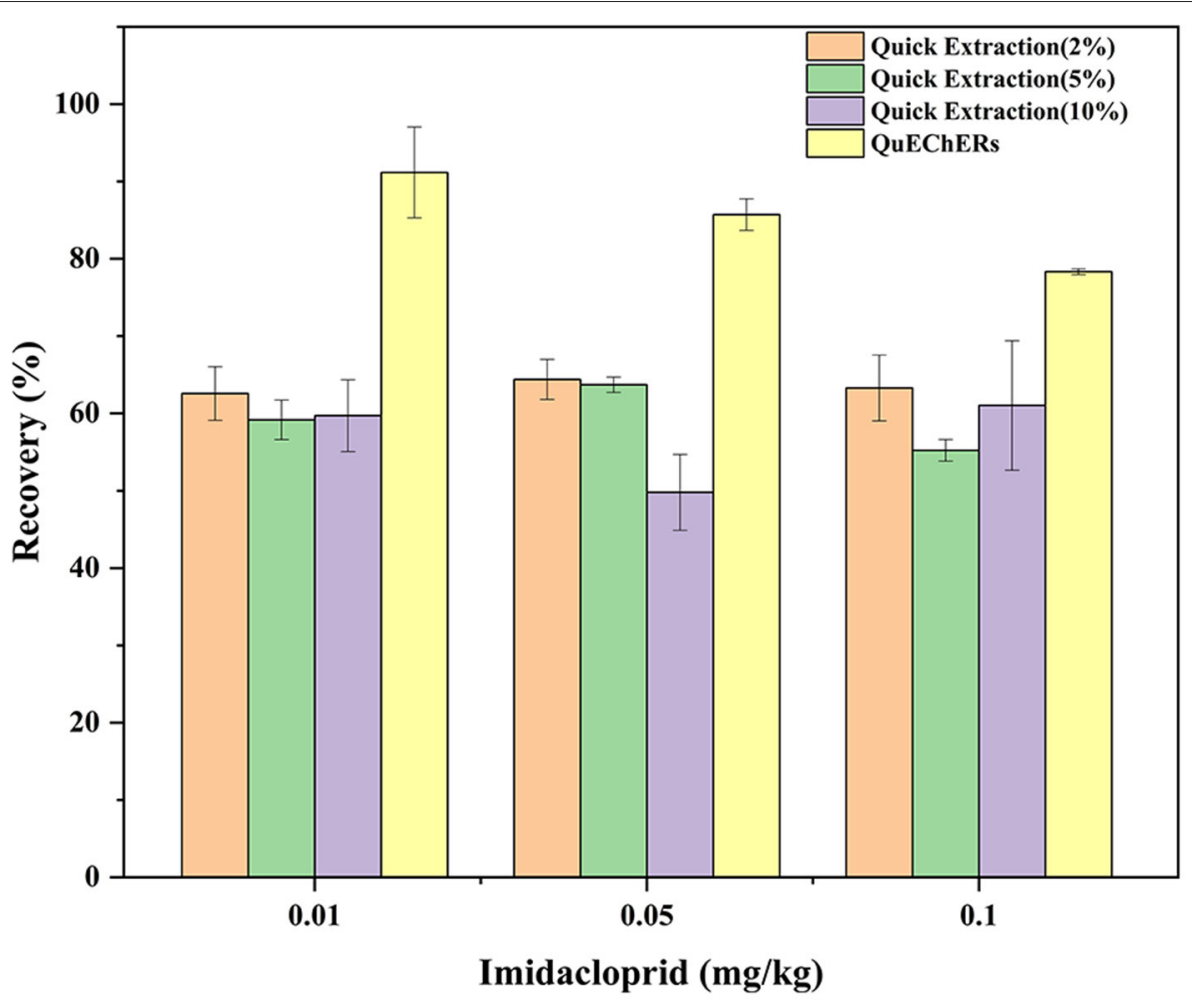

FIGURE 2 | Average recovery of spiked levels using QuEChERS and Quick extraction in Chinese chive.

TABLE 3 | Recoveries and relative standard deviations (RSD) of imidacloprid in Chinese chives.

\begin{tabular}{|c|c|c|c|c|c|c|c|c|}
\hline \multirow{3}{*}{$\begin{array}{l}\text { Spiked } \\
(\mathrm{mg} / \mathrm{kg})\end{array}$} & \multicolumn{2}{|c|}{ QuEChERS } & \multicolumn{6}{|c|}{ Quick extraction } \\
\hline & \multirow[b]{2}{*}{ Recovery (\%) } & \multirow[b]{2}{*}{ RSD (\%) } & \multicolumn{2}{|c|}{ Methanol (2\%) } & \multicolumn{2}{|c|}{ Methanol (5\%) } & \multicolumn{2}{|c|}{ Methanol (10\%) } \\
\hline & & & Recovery (\%) & RSD (\%) & Recovery (\%) & RSD (\%) & Recovery (\%) & RSD (\%) \\
\hline 0.01 & 91.17 & 6.43 & 62.57 & 5.54 & 59.18 & 4.31 & 59.71 & 7.78 \\
\hline 0.05 & 85.72 & 2.37 & 64.40 & 4.02 & 63.71 & 1.55 & 49.80 & 9.85 \\
\hline 0.1 & 78.34 & 0.48 & 63.29 & 6.73 & 55.22 & 2.53 & 61.03 & 13.71 \\
\hline
\end{tabular}

TABLE 4 | Dissipation kinetic equations, half-lives, and other related parameters of imidacloprid in Chinese chives.

\begin{tabular}{cccc}
\hline $\begin{array}{c}\text { Initial deposit } \\
(\mathbf{m g} / \mathbf{k g})\end{array}$ & $\begin{array}{c}\text { Dissipation kinetic } \\
\text { equations }\end{array}$ & $\begin{array}{c}\text { Correlation coefficient } \\
\left(\boldsymbol{R}^{\mathbf{2}}\right)\end{array}$ & $\begin{array}{c}\text { Half-life } \\
\text { (d) }\end{array}$ \\
\hline 0.1666 & $C_{t}=165.290 e^{-0.108 t}$ & $R^{2}=0.9831$ & 2.92 \\
\hline
\end{tabular}

concentration levels $(0.01,0.05$, and $0.1 \mathrm{mg} / \mathrm{kg})$ of imidacloprid to a blank matrix in six replicates $(n=6)$ (Figure 2). The results are summarized in Table 3. We tested acetonitrile, ethyl acetate, acetone, and methanol as an extraction solvent to determine the imidacloprid residues in agricultural products (22). It has to be noted that acetonitrile is more expensive and toxic, ethyl acetate is not miscible with an aqueous solution, and acetone requires availability to purchase the organic solvents. Hence, all the above organic solvents were excluded (2325). We have chosen methanol as a quick extraction solvent. Methanol has low environmental toxicity, cheap, and easy to obtain. To obtain a satisfactory recovery, different ratios of aqueous methanol solutions were optimized. The average recoveries of imidacloprid were $62.57-64.40 \%, 55.22-63.71 \%$, and $49.80-61.03 \%$ with RSD between 4.02 and $6.73 \%, 1.55$ and $4.31 \%$, and 7.78 and $13.71 \%$ using an aqueous solution of 2, 5, and $10 \%$ methanol, respectively. The recovery is inconsistent with the standard NY/T 788-2018 using methanol aqueous solution as an extractant. Thus, the ratio and composition of the extractant need to be further improved. On the other hand, the average recoveries of imidacloprid were $78.34-91.17 \%$, with RSD between 0.48 and $6.43 \%$ using 


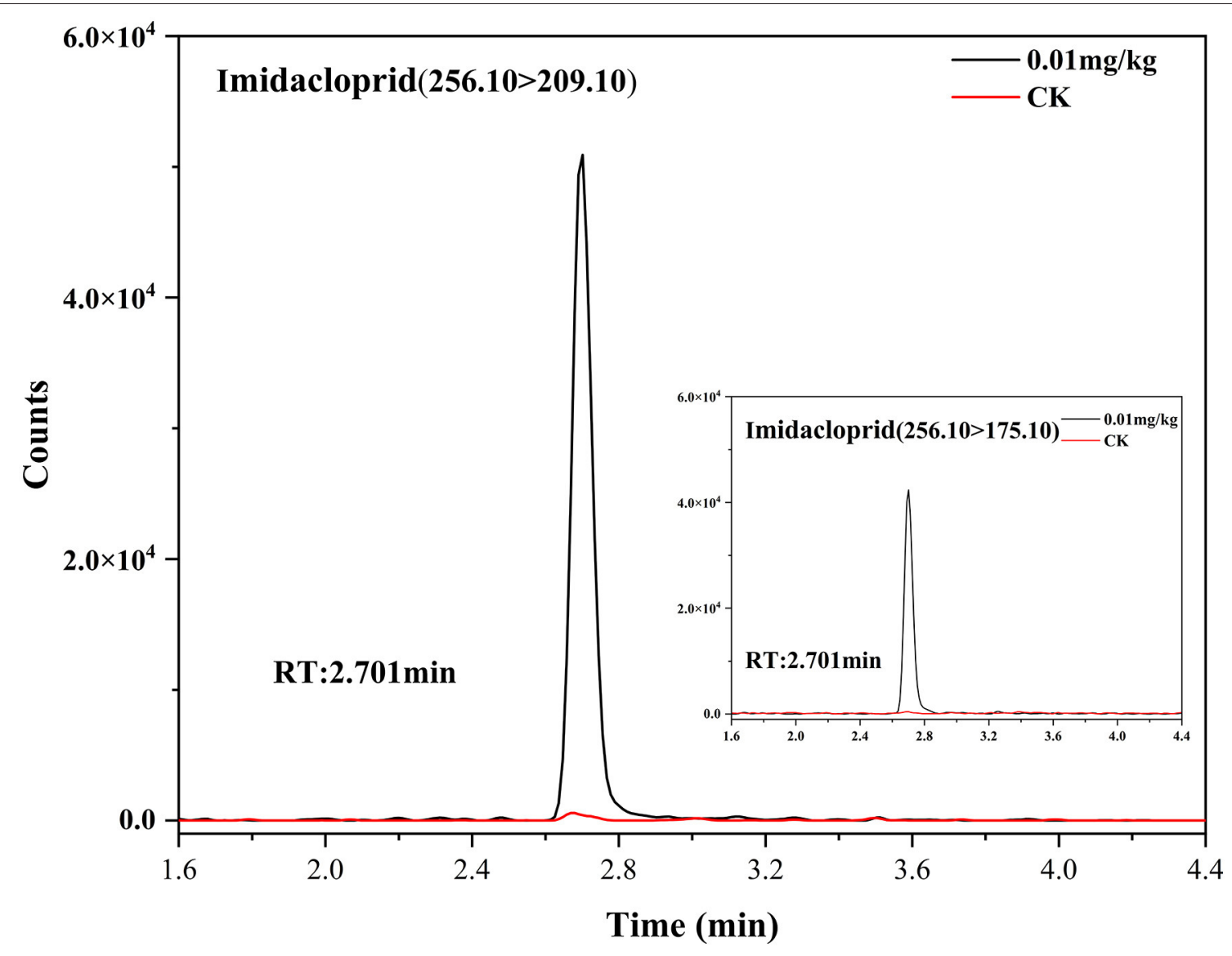

FIGURE 3 | Extracted ion chromatograms of imidacloprid in control and spiked sample $(0.01 \mathrm{mg} / \mathrm{kg})$ for Chinese chive.

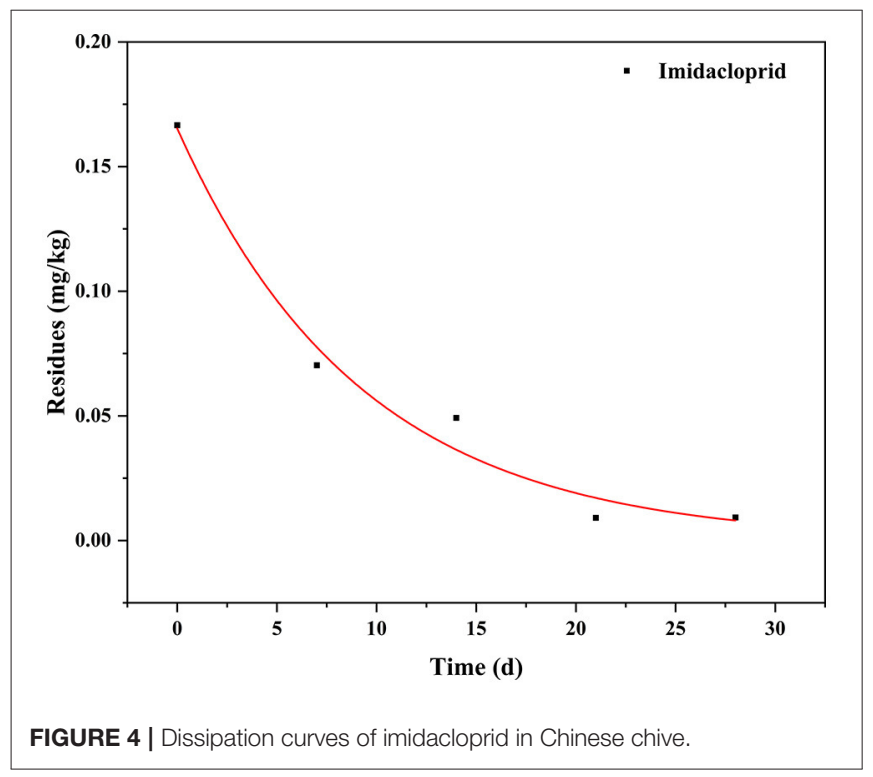

QuEChERS in Chinese chives, which met the experimental criteria. The extracted ion chromatograms of imidacloprid in blank and spiked samples are shown in Figure 3. The following method validation and dissipation dynamics were performed using QuEChERS.

In QuEChERS, the adsorbents PSA, C-18, and GCB were used to adsorb organic acids, vitamins, and pigments. Moreover, anhydrous magnesium sulfate and sodium chloride were used to remove the water from the samples $(22,26)$. Most importantly, extraction with $100 \%$ acetonitrile results in higher recoveries. The quick extraction method used different ratios of methanolic aqueous solutions without purification. The steps of salting out and purification had less effect on the extraction rate of imidacloprid in the QuEChERS method. The main reason for the high extraction rate of QuEChERS was that the acetonitrile is more polar than methanol, and its proportion was $100 \%$. The proportion of organic solvent was higher, contributing to the high extraction efficiency of the QuEChERS method.

\section{Dissipation of Imidacloprid in Chinese Chives}

The dissipation data and curves of imidacloprid in Chinese chives are shown in Table 4 and Figure 4. The dissipation dynamic under field conditions followed a first-order kinetics model, with correlation coefficients $\left(R^{2}\right)$ of 0.9831 . The dissipation dynamics show a fast pre-late stage and a flat mid-stage. The 
TABLE 5 | Effect of different factors on imidacloprid dissipation.

\begin{tabular}{|c|c|c|c|c|c|c|c|}
\hline Crop type & Volume & Application times & Application interval (d) & Mix with other pesticides & $R^{2}$ & Half-time (d) & References \\
\hline Tomato & $2.5 \mathrm{~L} \mathrm{ha} \mathrm{h}^{-1}$ & 1 & - & No & 0.90 & 14.43 & (29) \\
\hline Rice & $20 \mathrm{~g}$ ai ha ${ }^{-1}$ & 2 & 10 & No & 0.992 & 7.16 & (30) \\
\hline Brinjal & $42 \mathrm{~g}_{\text {ai ha }} \mathrm{h}^{-1}$ & 3 & 7 & No & - & 2.31 & (31) \\
\hline Cardamom & $20 \mathrm{~g}_{\text {ai ha }} \mathrm{h}^{-1}$ & 1 & - & No & 0.98 & 3.63 & $(32)$ \\
\hline Green chilies & $20 \mathrm{~g} \mathrm{ai} \mathrm{ha}^{-1}$ & 2 & 7 & No & 0.996 & 2.08 & (33) \\
\hline Tea & $30 \mathrm{~g}_{\text {ai ha }}{ }^{-1}$ & 1 & - & No & 0.972 & 2.45 & (34) \\
\hline Cabbage & $32.38 \mathrm{~g} \mathrm{ha}^{-1}$ & 1 & - & No & 0.934 & 33.0 & (35) \\
\hline Celery & $56.2 \mathrm{~g}$ ai ha ${ }^{-1}$ & 1 & - & Yes & 0.99 & 46.5 & $(36)$ \\
\hline
\end{tabular}

TABLE 6 | Dietary exposure risk assessment.

\begin{tabular}{|c|c|c|c|c|c|c|c|c|}
\hline Matrix & $\begin{array}{l}\text { PHI } \\
\text { (d) }\end{array}$ & $\begin{array}{l}\text { Residue } \\
\text { (mg/ kg) }\end{array}$ & $\begin{array}{c}\text { STMR } \\
\text { (mg/ kg) }\end{array}$ & $\begin{array}{c}\text { NEDI } \\
(\mathrm{mg} / \mathrm{kg} \cdot \mathrm{bw} / \mathrm{d})\end{array}$ & $\begin{array}{l}\text { RQc } \\
(\%)\end{array}$ & $\begin{array}{c}\mathrm{HR} \\
(\mathrm{mg} / \mathrm{kg})\end{array}$ & $\begin{array}{c}\text { NESTI } \\
(\mathrm{mg} / \mathrm{kg} \mathrm{bw} / \mathrm{d})\end{array}$ & $\begin{array}{l}\text { RQa } \\
(\%)\end{array}$ \\
\hline \multirow[t]{2}{*}{ Chinese chives } & 7 & 0.0703 & 0.0703 & 0.000102 & 0.170 & 0.167 & 0.00132 & 0.331 \\
\hline & 14 & 0.0492 & 0.0492 & 0.0000715 & 0.119 & 0.0703 & 0.000558 & 0.139 \\
\hline
\end{tabular}

initial residues were $0.1666 \mathrm{mg} / \mathrm{kg}$ with half-lives $\left(\mathrm{T}_{1 / 2}\right)$ of 2.92 days. Approximately $90 \%$ of imidacloprid residues were dissipated 28 days after application. The dissipation dynamics suggested that imidacloprid is readily degraded in Chinese chives during its growth. Other experimental field studies have shown that the dissipation dynamics of imidacloprid are affected by various factors, including crop type, climate and environmental conditions, application dose and timing, and co-application with other pesticides $(27,28)$. In this context, Li et al. (29) investigated the final residues and the dissipation dynamics of imidacloprid in tomatoes by LC-MS/MS, with a half-life of 14.43 days and $R^{2}=0.90$. Imidacloprid in tomatoes decreased rapidly during the first 7 days. It tended to decrease slowly after 14 days, consistent with a rapid degradation trend in the first period and a slight decrease in the second period. The same trend of imidacloprid dissipation was observed in other crops, as detailed in Table 5. The present study is consistent with previous studies, presenting trends in line with each other. Different crop types and environmental factors can influence the dissipation of imidacloprid. However, volatilization is the main factor of imidacloprid dissipation under outdoor conditions, leading to imidacloprid dissipation (37).

\section{Dietary Exposure Assessment}

The acute and chronic dietary risk of total residues of imidacloprid in Chinese chives was assessed (Table 6). For a Chinese adult weighing $63 \mathrm{~kg}$, the average consumption of Chinese chives was $0.0915 \mathrm{~kg} / \mathrm{d}$, and the ADI of imidacloprid was $0.06 \mathrm{mg} / \mathrm{kg}$ bw/day. According to Eqs. (3)-(4), the RQc of imidacloprid was $0.119-0.170 \%$ in Chinese chives, which is $<100 \%$. The large portion that is reported for Chinese chives was $0.5 \mathrm{~kg} / \mathrm{d}$. The highest residue of Chinese chives was $0.167 \mathrm{mg} / \mathrm{kg}$. The ARfD of imidacloprid was established to be $0.4 \mathrm{mg} / \mathrm{kg}$ bw/day. According to Eqs. (5)-(6), the RQa of imidacloprid was $0.139-0.331 \%$ in Chinese chives, which is $<100 \%$. These results suggest that the acute and chronic dietary risk of imidacloprid is not threatening the health of the average Chinese consumers for Chinese chives.

Moreover, the Fi ratio of different age groups to the body weight was significantly different. Therefore, 6 distinct groups were selected, representing young children (2-4 years old), young adults (18-30 years old), and elderly (60-70 years old) for risk assessment. The NEDI and RQc were calculated by combining data on diet, bodyweight of Chinese, and the final residues of imidacloprid in Chinese chives determined in this study (38). In addition, the highest STMR (0.0703 $\mathrm{mg} / \mathrm{kg}$ ) at the recommended PHI (7 days) in the final residues was selected for evaluation. Following the principle of risk maximization, the Fi of Chinese chives was calculated using the vegetable. Table 7 shows that the RQc was $<100 \%$ and decreased gradually with age. The RQc of children $(2-4$ years old) was the highest. The dietary exposure of females was slightly higher than that of males in the same age group due to differences in body weight and dietary habits between the sexes.

\section{CONCLUSION}

Herein, imidacloprid residual levels and dissipation dynamics on Chinese chives under outdoor conditions were determined using QuERChERS preparation and LC-MS/MS based on the application dose, frequency, and harvest interval criteria implemented in NY/788-2018. Furthermore, risk assessment was performed according to the risk quotient method. The pattern of imidacloprid dissipation in Chinese chives was best fitted to 
TABLE 7 | The exposure risk of imidacloprid among different age groups in China.

\begin{tabular}{|c|c|c|c|c|c|}
\hline Age & Gender $^{a}$ & $\mathrm{Fi}(\mathrm{kg} / \mathrm{d})$ & $B w(k g)$ & $\mathrm{NEDI}(\mathrm{mg} / \mathrm{kg} \cdot \mathrm{bw} / \mathrm{d})$ & RQc (\%) \\
\hline \multirow[t]{2}{*}{$2-4$} & M & 0.2234 & 14.1 & 0.00111 & 1.86 \\
\hline & $\mathrm{F}$ & 0.2234 & 13.4 & 0.00117 & 1.95 \\
\hline \multirow[t]{2}{*}{$18-30$} & M & 0.3550 & 60.5 & 0.000412 & 0.687 \\
\hline & F & 0.3550 & 52.6 & 0.000474 & 0.791 \\
\hline 60-70 & M & 0.3664 & 61.3 & 0.000420 & 0.700 \\
\hline
\end{tabular}

${ }^{a} M$, male; F, female.

first-order kinetics with a half-life of 2.92 days. A recommended dosage of $10 \%$ WG under outdoor conditions and a spray interval of 7 days will not cause any harm to humans.

\section{DATA AVAILABILITY STATEMENT}

The original contributions presented in the study are included in the article/supplementary material, further inquiries can be directed to the corresponding authors.

\section{AUTHOR CONTRIBUTIONS}

RZ, KZ, and GC: investigation and writing - original draft. GL, $\mathrm{XH}, \mathrm{MG}$, and JZ: investigation and visualization. XX, LL, and YZ:

\section{REFERENCES}

1. Zhang WN, Zhang HL, Lu CQ, Luo JP, Zha XQ. A new kinetic model of ultrasound-assisted extraction of polysaccharides from Chinese chive. Food Chem. (2016) 212:274-81. doi: 10.1016/j.foodchem.2016.05.144

2. Gao Q, Li XB, Sun J, Xia ED, Tang F, Cao HQ, et al. Isolation and identification of new chemical constituents from Chinese chive (Allium tuberosum) and toxicological evaluation of raw and cooked Chinese chive. Food Chem Toxicol. (2018) 112:400-11. doi: 10.1016/j.fct.2017.02.011

3. Nishiwaki Y, Takahashi T, Wada E, Nishimura Y. Nondestructive Mineral Imaging of Chinese Chive Leaves Withered by Physiological Damage Using Microbeam Synchrotron Radiation X-Ray Fluorescence Analysis. Anal Sci. (2021) 37:1459-63. doi: 10.2116/analsci.21N002

4. Tang $\mathrm{X}$, Olatunji OJ, Zhou Y, Hou X. Allium tuberosum: Antidiabetic and hepatoprotective activities. Food Res Int. (2017) 102:681-9. doi: 10.1016/j.foodres.2017.08.034

5. Mosavat SH, Ghahramani L, Sobhani Z, Haghighi ER, Chaijan MR, Heydari M. The effect of leek (Allium iranicum (Wendelbo)) leaves extract cream on hemorrhoid patients: A double blind randomized controlled clinical trial. Eur J Integr Med. (2015) 7:669-73. doi: 10.1016/j.eujim.2015.08. 008

6. Thompson CM, Gaylor DW, Tachovsky JA, Perry C, Carakostas MC, Haws LC. Development of a chronic noncancer oral reference dose and drinking water screening level for sulfolane using benchmark dose modeling. J Appl Toxicol. (2013) 33:1395-406. doi: 10.1002/jat.2799

7. Strati IF, Kostomitsopoulos G, Lytras F, Zoumpoulakis P, Proestos C, Sinanoglou VJ. Optimization of Polyphenol Extraction from Allium ampeloprasum var. porrum through Response Surface Methodology. Foods. (2018) 7:162. doi: 10.3390/foods7100162

8. Oh M, Kim SY, Park S, Kim KN, Kim SH. Phytochemicals in Chinese Chive (Allium tuberosum) Induce the Skeletal Muscle Cell Proliferation via PI3K/Akt/mTOR and Smad Pathways in C2C12 Cells. Int J Mol Sci. (2021) 22:2296. doi: 10.3390/ijms22052296 visualization and supervision. JW, MJ, DX, and AA: validation and writing - review and editing. All authors contributed to the article and approved the submitted version.

\section{FUNDING}

This study was financially supported by Central Public-interest Scientific Institution Basal Research Fund, Chinese Academy of Agricultural Sciences (IVF-BRF2021020), the Agricultural Science and Technology Innovation Program of CAAS (CAASZDRW202011, CAAS-TCX2019025-5), the China Agriculture Research System of MOF and MARA (CARS-23-E03), and the National Key Research Development Program of China (2020YFD1000300).
9. Yan $\mathrm{H}$, Zhang B, Wang E, Xu X, Wei GS. Combining predatory mites and film mulching to control Bradysiacellarum (Diptera: Sciaridae) on Chinese chives, Allium tuberosum. Exp Appl Acarol. (2022) 86:11727. doi: 10.1007/s10493-021-00681-9

10. Gul H, Ullah F, Hafeez M, Tariq K, Desneux N, Gao X, et al. Sublethal concentrations of clothianidin affect fecundity and key demographic parameters of the chive maggot, Bradysiaodoriphaga. Ecotoxicology. (2021) 30:1150-60. doi: 10.1007/s10646-021-02446-x

11. Ding Q, Xu X, Sang Z, Wang R, Ullah F, Gao X, et al. Characterization of the insecticide detoxification carboxylesterase Boest1 from Bradysiaodoriphaga Yang et Zhang (Diptera: Sciaridae). Pest Manag Sci. (2021) 78:591602. doi: $10.1002 /$ ps.6667

12. Loser D, Grillberger K, Hinojosa MG, Blum J, Haufe Y, Danker $\mathrm{T}$, et al. Acute effects of the imidacloprid metabolite desnitroimidacloprid on human nACh receptors relevant for neuronal signaling. Arch Toxicol. (2021) 95:3695-716. doi: 10.1007/s00204-021-0 3168-z

13. Chen C, Shi X, Desneux N, Han P, Gao X. Detection of insecticide resistance in Bradysiaodoriphaga Yang et Zhang (Diptera: Sciaridae) in China. Ecotoxicology. (2017) 26:868-75. doi: 10.1007/s10646-017-1817-0

14. Zhou Y, Piao X, Liao X, Liu J, Zhu H, Ma H, et al. Determination and chronic dietary exposure assessment ofprocymidone residue in Chinese chives. Chin J of Pesticide Sci. (2021) 23:373-9. doi: 10.16801/j.issn.1008-7303.2021.0007

15. Liu J, Hu Y, Yang Y, Zhang J, Zhong H, Liu L. Residue Level and Digestion Rate of Procymidone in Chinese Chives. Agrochemicals. (2021) 60:756-8. doi: 10.16820/j.cnki.1006-0413.2021.10.012

16. Lv B, Liu M, Xing S. Analysis of the national food safety supervision and sampling inspectionresult on vegetables in 2018. J Food Saf Qual. (2019) 10:5715-21. doi: 10.19812/j.cnki.jfsq11-5956/ts.2019.17.027

17. Yang L, Zhou X, Deng Y, Gong D, Luo H, Zhu P. Dissipation behavior, residue distribution, and dietary risk assessment of fluopimomide and dimethomorph in taro using HPLC-MS/MS. Environ Sci Pollut Res Int. (2021) 28:4395669. doi: $10.1007 / \mathrm{s} 11356-021-13713-\mathrm{z}$ 
18. Mao J, Li H, Chen Z, Zhang W, Guo C, Fang L, et al. Dissipation Dynamics and Preliminary Dietary Risk Assessment of Clothianidin and Cyromazine in Chinese Chives. Shandong Agric Sci. (2019) 51:118-23. doi: 10.14083/j.issn.1001-4942.2019.03.025

19. Zhang Q, Qin Z, Bai X, Jiang J. The acute dietary risk assessment of pesticide residues from fresh edible vegetables for human health. Chin Agri Sci Bulletin. (2013) 29:200-5. doi: 10.16498/j.cnki.hnnykx.20013.29.032

20. Zhou J, Dong C, An W, Zhao Q, Zhang Y, Li Z, et al. Dissipation of imidacloprid and its metabolites in Chinese prickly ash (Zanthoxylum) and their dietary risk assessment. Ecotoxicol Environ Saf. (2021) 225:112719. doi: 10.1016/j.ecoenv.2021.112719

21. Fu Y, Wang Q, Zhang L, Ling S, Jia H, Wu Y. Dissipation, occurrence, and risk assessment of 12 pesticides in Dendrobium officinale Kimura et Migo. Ecotoxicol Environ Saf. (2021) 222:112487. doi: 10.1016/j.ecoenv.2021.112487

22. Zhang C, Deng Y, Zheng J, Zhang Y, Yang L, Liao C, et al. The application of the QuEChERS methodology in the determination of antibiotics in food: a review. TrAC Trends Anal Chem. (2019) 118:517-37. doi: 10.1016/j.trac.2019.06.012

23. Aguilera-Luiz MM, Martínez Vidal JL, Romero-González R, Garrido Frenich A. Multiclass method for fast determination of veterinary drug residues in baby food by ultra-high-performance liquid chromatography-tandem mass spectrometry. Food Chem. (2012) 132:2171-80. doi: 10.1016/j.foodchem.2011.12.042

24. Herrera-Herrera AV, Hernandez-Borges J, Rodriguez-Delgado MA. Fluoroquinolone antibiotic determination in bovine, ovine and caprine milk using solid-phase extraction and high-performance liquid chromatographyfluorescence detection with ionic liquids as mobile phase additives. $J$ Chromatogr A. (2009) 1216:7281-7. doi: 10.1016/j.chroma.2009.02.025

25. Lombardo-Agüí M, García-Campaña AM, Cruces-Blanco C, GámizGracia L. Determination of quinolones in fish by ultra-high performance liquid chromatography with fluorescence detection using QuEChERS as sample treatment. Food Control. (2015) 50:864-8. doi: 10.1016/j.foodcont.2014.10.027

26. Qi P, Wang J, Liu Z, Wang Z, Xu H, Di S, et al. Integrated QuEChERS strategy for high-throughput multi-pesticide residues analysis of vegetables. J Chromatogr A. (2021) 1659:462589. doi: 10.1016/j.chroma.2021.462589

27. Zhang Q, Wang X, Rao Q, Chen S, Song W. Imidacloprid dissipation, metabolism and accumulation in Agaricusbisporus fruits, casing soil and compost and dietary risk assessment. Chemosphere. (2020) 254:126837. doi: 10.1016/j.chemosphere.2020.126837

28. Yen JH, Liao CS, Kuo YW, Chen WC, Huang WT. Effect of growing groundcover plants in a vineyard on dissipation of two neonicotinoid insecticides. Sustainability. (2019) 11:798. doi: 10.3390/su11030798

29. Li J, Jiang Y, Li D. Determination of imidacloprid and its relevant metabolites in tomato using modified QuEChERS combined with ultrahigh-pressure liquid chromatography/Orbitrap tandem mass spectrometry. J Sci Food Agric. (2019) 99:5211-8. doi: 10.1002/jsfa.9769

30. Akoijam R, Singh B. Persistence and metabolism of imidacloprid in rice. Bull Environ ContamToxicol. (2014) 92:609-15. doi: 10.1007/s00128-013-1190-5
31. Mandal K, Chahil GS, Sahoo SK, Battu RS, Singh B. Dissipation kinetics of beta-cyfluthrin and imidacloprid in brinjal and soil under subtropical conditions of Punjab, India. Bull Environ Contam Toxicol. (2010) 84:2259. doi: 10.1007/s00128-009-9903-5

32. Pratheeshkumar N, Chandran M, Beevi SN, Mathew TB, George T, Paul A, et al. Dissipation kinetics and effect of processing on imidacloprid and its metabolites in cardamom (Elettaria cardamomum Maton). Environ Monit Assess. (2016) 188:53. doi: 10.1007/s10661-015-50 58-5

33. Varghese TS, Mathew TB, George T, Beevi SN, Xavier G. Persistence and dissipation of neonicotinoid insecticides on chilli fruits. Qual Assur Saf Crops Foods. (2015) 7:487-91. doi: 10.3920/QAS2013.0265

34. Hou RY, Hu JF, Qian XS, Su T, Wang XH, Zhao XX, et al. Comparison of the dissipation behaviour of three neonicotinoid insecticides in tea. Food Addit Contam Part A Chem Anal Control Expo Risk Assess. (2013) 30:17619. doi: 10.1080/19440049.2013.820356

35. Chen Y, Nie E, Huang L, Lu Y, Gao X, Akhtar K, et al. Translocation and metabolism of imidacloprid in cabbage: Application of (14)C-labelling and LC-QTOF-MS. Chemosphere. (2021) 263:127928. doi: 10.1016/j.chemosphere.2020.127928

36. Kang L, Liu H, Zhao D, Pan C, Wang C. Pesticide Residue Behavior and Risk Assessment in Celery after Se Nanoparticles Application. Foods. (2021) 10:1987. doi: 10.3390/foods10091987

37. Celik S, Kunc S, Asan T. Degradation of some pesticides in the field and effect of processing. Analyst. (1995) 120:1739-43. doi: 10.1039/AN99520 01739

38. Yang Q, Ji M, Zu G. Residues behavior and dietary exposure risk assessment of cyazofamid and its main metabolite CCIM in tomato and grape. Chin J Pesticide Sci. (2020) 22:815-22. doi: 10.16801/j.issn.1008-7303.2020.0094

Conflict of Interest: The authors declare that the research was conducted in the absence of any commercial or financial relationships that could be construed as a potential conflict of interest.

Publisher's Note: All claims expressed in this article are solely those of the authors and do not necessarily represent those of their affiliated organizations, or those of the publisher, the editors and the reviewers. Any product that may be evaluated in this article, or claim that may be made by its manufacturer, is not guaranteed or endorsed by the publisher.

Copyright (C) 2022 Zhai, Zhang, Chen, Liu, Huang, Gao, Zhou, Xu, Li, Zhang, Wang, Jin, $X u$ and Abd El-Aty. This is an open-access article distributed under the terms of the Creative Commons Attribution License (CC BY). The use, distribution or reproduction in other forums is permitted, provided the original author(s) and the copyright owner(s) are credited and that the original publication in this journal is cited, in accordance with accepted academic practice. No use, distribution or reproduction is permitted which does not comply with these terms. 